\title{
RELATIONSHIP BETWEEN CYTOLOGICAL GRADING OF BREAST CANCERS AND LYMPH NODE METASTASIS
}

\author{
Farooq Ahmed Wani' ${ }^{1}$, Subhash Bhardwaj ${ }^{2}$, Dinesh Kumar ${ }^{3}$, Pervez Katoch ${ }^{2}$, Altaf Hussain Bandy ${ }^{4}$ \\ 1 Department of Pathology, Aljouf College of Medicine, Sakaka, Saudi Arabia \\ 2 Department of Pathology, Government Medical College, Jammu, India \\ 3 Department of Community Medicine, Government Medical College, Jammu, India \\ 4 Department of Community Medicine, Aljouf College of Medicine, Sakaka, Saudi Arabia
}

Correspondence to: Farooq Ahmed Wani (wani_farooq786@yahoo.com)

DOI: 10.5455/ijmsph.2014.190520141 Received Date: 14.05.2014 Accepted Date: 29.05.2014

\begin{abstract}
Background: Breast cancer is the second most common type of cancer and the second leading cause of cancer related deaths in females. Since a less invasive pre-operative diagnosis is always preferred to open biopsy, fine needle aspiration cytology has been frequently used to decide the benign or malignant nature of particular breast lesions. But many studies have shown that this technique can provide additional information about the intrinsic features of the tumours as well as their prognosis. Grading of breast carcinoma, while the tumour is still in vivo, would be the most ideal and desirable situation, as it would be helpful in the selection of patients for appropriate therapy.

Aims \& Objective: (i) To evaluate and compare the cytograding of breast cancers using Robinson's and Mouriquand's grading methods. (ii) To evaluate the relationship between cytograding of breast cancers and lymph node metastasis.

Materials and Methods: A 5-year retrospective (from Oct 2000 to Sept 2005) and 1-year prospective study (from 0ct 2005to Oct 2006). A total of 110 fine-needle aspiration cytology (FNAC) cases of breast cancers were graded by Robinson's and Mouriquand's grading methods followed by comparison of the two methods. Relationship between grading and lymph node metastasis was evaluated.

Results: By Robinson's method, 28 (25.45\%) cases were grade I, 46 (41.81\%) grade II and 36 (32.72\%) were grade III whereas using Mouriquand's method, 28 (25.45\%), 42 (38.18\%) and 40 (36.36\%) cases were graded as grade I, II, and III respectively. A high degree of concordance was observed between the two grading methods (90.9\%). A highly significant relationship between the scores obtained by two methods was also observed $(\mathrm{P}=0.004)$. By Robinson's method, Grade I, II and III tumours had lymph node involvement in $3.57 \%, 6.52 \%$ and $47.22 \%$ of cases respectively whereas by Mouriquand's method, Grade I, II and III tumours had lymph node involvement in $3.57 \%, 7.14 \%$ and $42.5 \%$ of cases respectively. Although both grading systems showed significant relationship with lymph node involvement but Robinson's grading was a much better predictor of lymph node metastasis. Our study showed that greater cell dissociation was associated with higher incidence of regional lymph node metastasis. A highly significant relationship was observed between cell dissociation and lymph node involvement $(\mathrm{p}=0.00000)$.

Conclusion: A comprehensive cytological grading of breast cancers is possible by using Robinson's and Mouriquand's method. A high degree of concordance was observed between the two methods but Robinson's grading system was found to be easier and better because of more objective set of criteria and easy reproducibility. Cytological grading of breast cancers is a strong predictor of lymph nodal metastasis and greater cell dissociation is associated with higher incidence of regional lymph node metastasis.

Key Words: Breast Cancer; Cytological Grading; Lymph Node Metastasis; Robinson's Method; Mouriquand's Method
\end{abstract}

\section{Introduction}

Breast cancer is the second most common type of cancer and the second leading cause of cancer related deaths in females.[1] Since a less invasive pre-operative diagnosis is always preferred to open biopsy, fine needle aspiration cytology has been frequently used to decide the benign or malignant nature of particular breast lesions. But many studies have shown that this technique can provide additional information about the intrinsic features of the tumours as well as their prognosis. [2] Grading of breast carcinoma, while the tumour is still in vivo, would be the most ideal and desirable situation, as it would be helpful in the selection of patients for appropriate therapy. ${ }^{[3]}$

The degree of cell dissociation is an indicator of cell cohesion status and to an extent, of the degree of expression of the Cadherin molecules on the cell surface. [4] Loss of cell cohesion appears to facilitate vascular infiltration by tumour cells, which gives rise to an increased incidence of regional lymph node metastasis. Greater cell dissociation has been found to be associated with higher incidence of regional lymph node metastasis. ${ }^{[5]}$ High cytological grade has also been found to be associated with nodal metastasis. ${ }^{[6]}$ As we know regional lymph node metastasis can predict the outcome of disease, therefore, cytological grade is a useful tool for predicting the prognosis of the patient.

Robles et al (2005) found that 3 out of 6 features of Robinson's grading system (nuclear margins, cell uniformity and cell dissociation) displayed a positive 
correlation with the presence of metastasis in axillary lymph nodes. Cancers with more pleomorphism and greater degree of cell dissociation tend to have greater incidence of regional lymph node metastasis. ${ }^{[2]}$

Fan et al proposed cytoprognostic scoring system based on nuclear grade, cellular dyscohesion and bare atypical nuclei. They found that high cytoprognostic score correlated with more positive lymph node metastasis and poor expression of prognostic markers. ${ }^{[7]}$

Our study aims to grade breast cancers by Robinson's and Mouriquand's methods and compare the two methods. We studied the relationship between cytograding and lymph node metastasis.

\section{Materials and Methods}

After obtaining clearance from Institutional Ethics Committee, all records regarding diagnosed or highly suspicious breast cancer cases (for the period starting from October 2000) were retrieved from the Cytological section of Department of Pathology, Govt. Medical College, Jammu. These records were then matched with the database of Breast cancer registered by the department of Radiotherapy and Surgical operation log books. Patients diagnosed at other institutions but receiving treatment in the hospital were excluded from the study. Retrospective study material comprised of 90 cases and prospective study material comprised of 20 new cases. These cases were referred from the department of Surgery or Radiotherapy for confirmation of diagnosis. All the patients referred were subjected to fine needle aspiration cytology and MGG and PAP staining was performed on the smears.

All the relevant clinical information provided in the requisition form was taken into consideration including age and sex of the patient; site, size and location of the tumour; condition of the overlying skin, fixity to underlying structures, history of nipple discharge; lymph node status. Grading of breast carcinoma was done according to Robinson's and Mouriquand's method by two independent observers. In case of disagreement between the two, the slides were shown to third observer and his decision was treated as final. In addition, parameters like tumour size, skin involvement and nipple discharge were also evaluated and their relationship with cytograding systems was studied.

Robinson's method takes into account following criteria: Cell dissociation (clusters/single cells), cell size (1-2/3-
4 / $\geq 5 \times$ RBC size), cell uniformity (monomorphic/mildly pleomorphic/pleomorphic), nucleoli (indistinct/ noticeable/ prominent), nuclear margins (smooth/ folds/ buds or tufts) and nuclear chromatin (vesicular/ granular/ clumped or cleaved). Each of the above criteria was given scores 1 - 3 and total sum of scores of all the criteria were used to grade tumours. Based on above mentioned criteria, breast cancers were graded into Grade - I (score 6 - 11), Grade - II (Score 12 - 14) and Grade III (Score 15-18) respectively.[8]

Mouriquand's Method takes into account the following criteria: - Cellular characters (clustering, 0 / isolated cells, 3), nuclear features (anisokaryosis, 2/ large cell, 3/ budding, 2/ naked, 3/ hyperchromasia, 2/ hypochromasia, nucleoli (blue, 2/red, 3) and number of mitosis ( $\geq 3 /$ slide $=1, \geq 6 /$ slide $=3$ ). Based on these criteria, breast cancers are graded into Grade I (score $<5$ ), Grade II (score 5 - 9) and Grade - III (Score $\geq 10$ ). [9]

\section{Statistical Analysis}

The data were analyzed with the help of computer software Microsoft Excel for Windows and Epi-Info Version 6.0, CDC, Atlanta, GA. Grading reported qualitatively in terms of percentages. The agreement between the methods was assessed by the use of Kappa statistics. Correlation between the scores evaluated using Spearman rank correlation and its significance evaluated using " $\mathrm{t}$ " test. A P value of less than 0.05 was considered as statistically significant. All $\mathrm{P}$ values used were two tailed.

\section{Results}

Of the 110 cases graded by Robinson's method, $28(25.45 \%)$ cases were grade I, 46 (41.81\%) grade II and $36(32.72 \%)$ cases were grade III tumours, whereas using Mouriquand's method, 28 (25.45\%) cases were grade I with scores $<5,42$ were grade III with scores $>10$ [Table 1].Of the 28 cases graded as grade I by Robinson's method,26 were graded as grade I, whereas two cases were over graded as grade II by Mouriquand's method. Most of the discordance was seen in grade II tumours. Of the 46 (41.81\%) cases graded as grade II by Robinson's method, 39 cases were graded as grade II, whereas two cases were under-graded as grade I and five cases were over-graded as grade III by Mouriquand's method. Of the 36 cases graded as grade III by Robinson's method, 35 cases were graded as grade III by Mouriquand's method and only one case was under-graded as grade II [Table 1]. 
Table-1: comparison of Robinson's and Mouriquand's grading Mouriquand's

Robinson's Grading

\begin{tabular}{ccccc} 
Grading & GI & GII & GIII & Total \\
\cline { 2 - 5 } GI & 26 & 2 & - & $28(25.45 \%)$ \\
\hline GII & 2 & 39 & 1 & $42(38.18 \%)$ \\
\hline GIII & - & 5 & 35 & $40(36.36 \%)$ \\
\hline Total & $28(25.45 \%)$ & $46(41.81 \%)$ & $36(32.72 \%)$ & $110(100 \%)$ \\
\hline $\begin{array}{l}\text { Unweighted kappa }=0.8615 ; \mathrm{SE}=0.0424 ; 95 \% \text { confidence limits }=0.7783 \text { to } \\
0.9447\end{array}$ & & &
\end{tabular}

Table-2: Correlation observed in scores obtained by Robinson's method and Mouriquand's method

\begin{tabular}{ccc} 
Criteria & Robinson's Scoring & Mouriquand's Scoring \\
\hline Minimum Score & 8 & 2 \\
\hline Maximum Score & 17 & 16 \\
\hline Mean Score & 13.12 & 8.027 \\
\hline Standard deviation & 0.235 & 0.371 \\
\hline Standard Error & 2.46 & 3.89 \\
\hline Correlation $=0.898 ;$ & $p=0.01(2$ tailed); $\gamma 2$ (correlation coefficient) $=$ \\
$0.8057 ; t=21.16 ; d f=108 ; p<0.0001$ (Highly significant)
\end{tabular}

Table-3: Lymph node involvement \& Robinson's grading Lymph Node Involvement

\begin{tabular}{|c|c|c|c|c|}
\hline \multirow[b]{2}{*}{ Grade } & & \multirow[b]{2}{*}{ Total } \\
\hline & $\begin{array}{c}\text { Palpable \& } \\
\text { Involved }\end{array}$ & $\begin{array}{c}\text { Palpable not } \\
\text { Involved }\end{array}$ & $\begin{array}{c}\text { Not } \\
\text { Palpable }\end{array}$ & \\
\hline I & $1(3.57 \%)$ & $3(10.71 \%)$ & $24(85.71 \%)$ & $28(25.45 \%)$ \\
\hline II & $3(6.52 \%)$ & $6(13.04 \%)$ & 37 (80.43\%) & $46(41.81 \%)$ \\
\hline III & $17(47.22 \%)$ & $1(2.77 \%)$ & $18(50 \%)$ & $36(32.72 \%)$ \\
\hline Total & $21(19.09 \%)$ & $10(9.09 \%)$ & $79(71.81 \%)$ & $110(100 \%)$ \\
\hline
\end{tabular}

Table-4: Lymph node involvement \& Mouriquand's grading

\begin{tabular}{ccccc} 
Grade & \multicolumn{2}{c}{ Lymph Node Involvement } & \multirow{2}{*}{ Total } \\
\cline { 2 - 5 } & $\begin{array}{c}\text { Palpable \& } \\
\text { Involved }\end{array}$ & $\begin{array}{c}\text { Palpable not } \\
\text { Involved }\end{array}$ & $\begin{array}{c}\text { Not } \\
\text { Palpable }\end{array}$ & \\
\hline I & $1(3.57 \%)$ & $3(10.71 \%)$ & $24(85.71 \%)$ & $28(25.45 \%)$ \\
\hline II & $3(7.14 \%)$ & $6(14.28 \%)$ & $31(73.80 \%)$ & $42(38.18 \%)$ \\
\hline III & $17(42.5 \%)$ & $1(2.5 \%)$ & $22(55 \%)$ & $40(36.36 \%)$ \\
\hline Total & $21(19.09 \%)$ & $10(9.09 \%)$ & $79(71.81 \%)$ & $110(100 \%)$ \\
\hline
\end{tabular}

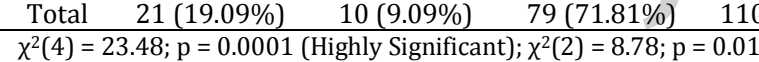

A high degree of concordance between Robinson's and Mouriquand's method was observed in our study. There was total agreement in $90.9 \%$ of the cases. Correlation of the scores obtained by Robinson's and Mouriquand's method is shown in Table 2. Our study showed a highly significant relationship between the scores obtained by Robinson's and Mouriquand's methods ( $P=0.004)$.

Of the 28 cases graded as grade I by Robinson's method, $1(3.57 \%)$ case had lymph node involvement. Grade II tumours had lymph node involvement in 3 (6.52\%) cases. Grade III tumours had a maximum lymph node involvement in 17(47.22\%) cases [Table 3]. Relationship between lymph node involvement and Robinson's grade was found to be highly significant in our study $(\mathrm{p}=0.0000)$.

Out of 28 cases reported as grade I by Mouriquand's method, only 1 (3.57\%) case had lymph node involvement. Grade II tumours had lymph node involvement in $3(7.14 \%)$ cases. Grade III tumours had lymph node involvement in 17 (42.5\%) cases [Table 4].
Relationship between lymph node involvement and Mouriquand's grading was highly significant in our study $(\mathrm{p}=0.0001)$.

In Robinson's grading, out of 21 cases showing lymph node involvement, 15 (71.42\%) cases showed cell dissociation score of 3 followed by 5 (23.80\%) cases showing cell dissociation score of 2 and $1(4.76 \%)$ case showing cell dissociation score of 1 [Table 2]. Highly significant relationship was found between cell dissociation scoring of Robinson's method and lymph node involvement $(\mathrm{p}=0.00000)$.

Relationship between the cytograding methods and tumour size, skin involvement and nipple discharge was found to be statistically insignificant in our study.

\section{Discussion}

Breast cancer is the second most prevalent cancer among Indian women, the first being cervical cancer.[10] In India, the breast is reported as the most common site of cancer in Mumbai and Thiruvananthapuram, whereas it is the second most common site of cancer in Chennai and Dibrugarh. In Bangalore, it is ranked third according to data reported from hospital-based cancer registries (ICMR).[11]

The purpose of cytoprognostic grading in breast cancers is to identify fast growing tumours (grade III), which are more likely to respond to chemotherapy than low grade, slow growing tumours, which may be better suited to pre-treatment with tamoxifen. Assessment of biological aggressiveness by cytological grading without removing the tumour would, therefore, be of immense value.[12]

In the present study, we found predominance of grade II tumours, which is in corroboration with those of previous studies. Robinson et al. reported grade II tumours (44\%) comprising the largest group. ${ }^{[8]}$ Chhabra et al. reported maximum number of cases as grade II (52\%) followed by grade I (30\%) and grade III (18\%).[13] Robles et al. also reported predominance of grade II tumours (39\%) followed by grade I (33\%) and grade III (28\%). However, in our study, grade III tumours formed the second largest group. The most probable reason for the grade III tumours forming the second largest group could be the late presentation of the patients in our set up. In our study, Mouriquand's grading showed a predominant grouping of cases into grade II (38.18\%), consistent with the findings reported by Pandit and Parekh.[14] 
Not many studies directly comparing the two grading methods could be found in the literature. Only one study conducted by Das et al. was retrieved from the literature, where they found total agreement in grading by both the methods in $76.9 \%$ cases. ${ }^{[15]}$ In our study, we found a high degree of concordance between Robinson's and Mouriquand's cytograding methods. There was a total agreement in $90.9 \%$ of the cases. However, few studies comparing different cytograding methods have shown similar results. In the study done by Bhargava et al., comparing Robinson's, Fischer's modification of Black's nuclear grading and Scarff-Bloom- Richardson methods, Robinson's grading system was found to have best correlation with histopathology grades as well as Estrogen Receptor/ Progesterone Receptor expression.[16]

In our study, some degree of discordance was observed between the two grading methods in all the grades with the majority of the discordant cases observed in grade II tumours. Of the $28(25.45 \%)$ cases graded as grade I by Robinson's method, 26 cases were graded as grade I, whereas two cases were over-graded as grade II by Mouriquand's method. Of the46 (41.81\%) cases graded as grade II by Robinson's method, 39 cases were graded as grade II by Mouriquand's method, whereas five cases were over-graded as grade III and two cases were undergraded as grade I. The reason for the over grading of the tumours by the Mouriquand's method appears to be the presence of mitosis in most of the discordant cases. Mitosis is one of the parameters used for grading by Mouriquand's method, whereas mitosis is not taken into consideration in Robinson's method. In the study done by Das et al., all the discordant cases were in grade II tumours but a minor degree of discordance was also observed in grade I and grade III tumours.

Our study showed a highly significant relationship between the scores obtained by Robinson's and Mouriquand's methods $(\mathrm{P}=0.004)$. A highly significant relationship was observed between lymph node involvement and Robinson's grading $(\mathrm{p}=0.0000)$ and between lymph node involvement and Mouriquand's grading $(\mathrm{p}=0.0001)$. These results are similar to earlier studies done by Mouriquand's et al (1980), Taniguchi et al (2000) and Robles et al (2005). Robles et al found that $88 \%$ of grade III tumours in their study had lymph nodal metastasis. ${ }^{[2]}$ We found that $47.22 \%$ of grade III tumours had lymph node involvement.

Furthermore, greater cell dissociation was associated with higher incidence of regional lymph node metastasis.
Out of 21 (19.09\%) cases showing lymph node involvement, 15 (71.42\%) showed a cell dissociation score of 3 when Robinson's grading was applied (Table3). A highly significant relationship was observed between cell dissociation and lymph node involvement $(\mathrm{p}=0.00000)$. Our findings were in accordance with previous studies conducted by Mouriquand et al (1980), Layfield et al (1992), and Robles et al (2005). Robles et al (2005) found that $86 \%$ of their patients with nodal metastasis had cell dissociation score 3. Mouriquand and Pasquier found that $66 \%$ of their patients with grade III carcinoma had local recurrence of disease, metastasis or death within one year of follow up. Layfield found that $57.14 \%$ of their patients with individual cell pattern had nodal metastasis. ${ }^{[17]}$

Schiller et al in their study failed to show cellular dyscohesion in FNA specimens as predictive of lymph node metastasis, however, the scoring method for determining the degree of cellular dyscohesion was reproducible between two independent observers. ${ }^{[18]}$ No statistically significant relationship was found between cytograding methods and tumour size, skin involvement and nipple discharge, consistent with the studies done by Layfield et al (1992) and Taniguchi et al (2000).

\section{Conclusion}

A comprehensive cytological grading of the breast cancers is possible by using two different methods proposed by Robinson and Mouriquand. In spite of a high degree of concordance between the two grading methods, the grading of breast cancers by Robinson's method has been found to be easier and better because of the more objective set of criteria and easy reproducibility. It is, however, important to draw the readers' attention to the fact that the conclusions drawn might have been affected by selection and measurement bias to some extent, in spite of adequate efforts having been made at the design stage to minimize the distortion in the estimates. Thus, it is suggested that a conscious effort should be made to include the cytological grading in all the FNAC reports of breast cancers, so that an appropriate decision regarding the preoperative neoadjuvant therapy can be taken and the overtreatment of low-grade cancers is avoided. Cytological grading of breast cancers is a strong predictor of lymph nodal metastasis; higher grade cancers were associated with higher incidence of lymph node metastasis. Furthermore greater cell dissociation was associated with higher incidence of regional lymph node metastasis. 


\section{References}

1. Lester SC. The breast. In: Robbins and Cotran, Pathologic basis of disease. Kumar V, Abbas A K, Fausto N, editors. 7th ed. Philadelphia: WB Saunders Company Elsevier Inc; 2004. p. 112931.

2. Robles Frías A, González-Cámpora R, Martínez-Parra D, RoblesFrías MJ, Vázquez-Cerezuela T, Otal-Salaverri C, et al. Robinson cytologic grading of invasive ductal breast carcinoma: Correlation with histologic grading and regional lymph node metastasis. Acta Cytol 2005;4:149-53.

3. Khan MZ, Haleem A, Hassani HA, Kfoury H. Cytopathological grading, as a predictor of histopathological grade, in ductal carcinoma (NOS) of breast, on air-dried Diff-Quick smears. Diagn Cytopathol 2003;29:185-93.

4. Yoshida R, Kimura N, Harada Y, Ohuchi N. The loss of E-cadherin, alpha- and beta-catenin expression is associated with metastasis and poor prognosis in invasive breast cancer. Int J Oncol 2001;18: 513-520.

5. Yu GH, Cajulis RS, De Frias DVS. Tumour cell (dys)cohesion as a prognostic factor in aspirate smears of breast carcinoma. Am J Clin Pathol 1998;109:315-319.

6. Taniguchi E, Yang Q, Tang W, Nakamura Y, Shan L, Nakamura M, et al. Cytologic grading of invasive breast carcinoma: Correlation with clinico pathologic variables and predictive value of nodal metastasis. Acta Cytol 2000; 44: 587-591.

7. Fan F, Namiq AL, Tawfik OW, Thomas PA. Proposed prognostic score for breast carcinoma on fine needle aspiration based on nuclear grade, cellular dyscohesion and bare atypical nuclei. Diagn Cytopathol 2006;34(8):542-546.

8. Robinson IA, McKee G, Nicholson A, D'Acry J, Jackson PA, Cook MG, et al. Prognostic value of cytological grading of fine-needle aspirates from breast carcinomas. Lancet 1994;343:947-9.

9. Mouriquand J, Pasquier D. Fine needle aspiration of breast carcinoma: A preliminary cytoprognostic study. Acta Cytol 1980;24:153-9.

10. Rao DN, Ganesh B. Estimate of cancer incidence in India in 1991. Indian J Cancer 1998;35:10-18.

11. National Cancer Registry Programme, ICMR - Five year consolidated report of the hospital based cancer registries (19941998), Bangalore, India 2002: http://icmr.nic.in/ncrp/cancer_reg.htm [Last Accessed 30th June 2008]

12. Katz RL. A turning point in breast cancer cytology reporting Moving from callowness to maturity. Acta Cytol 1994;38:881-883.

13. Chhabra S, Singh PK, Agarwal A, Singh SN, Bhagoliwal A Cytological grading of breast carcinoma - a multivariate regression analysis. J Cytol 2005;22:62-5.

14. Pandit AA, Parekh HJ. Cytologic grading of breast carcinoma: comparison of four grading systems. J Cytol 2000;17:39-44.

15. Das AK, Kapila K, Dinda AK, Verma K. Comparative evaluation of grading of breast carcinomas in fine needle aspirates by two methods. Indian J Med Res 2003;118:247-50.

16. Bhargava V, Jain $M$, Agarwal $K$, Thomas S, Singh S. Critical appraisal of cytological nuclear grading in carcinoma of the breast and its correlation with ER/PR expression. J Cytol 2008;25:58-61.

17. Layfield LJ, Robert ME, Cramer $\mathrm{H}$ et al: Aspirator biopsy smear pattern as a predictor of biologic behaviour in adenocarcinoma of breast. Acta Cytol 1992; 36: 208-214.

18. Schiller AB, Tadros TS, Birdsong GG et al: Cellular dyscohesion in fine needle aspiration of breast carcinoma. Prognostic indicator for axillary lymph node metastases? Am J Clin Pathol 2001; 115(2): 219-223. 